\title{
IL-1ß-Mediated Up-Regulation of WT1D via miR-144-3p and Their Synergistic Effect with NF-kB/COX-2/HIF-1 $\alpha$ Pathway on Cell Proliferation in LUAD
}

\author{
Chen Wu $u^{a, b, c}$ Xiaodong Lia,c Dachuan Zhange Bin Xu ${ }^{c, d}$ Wenwei Hu $u^{a, b, c}$ \\ Xiao Zheng ${ }^{b, c, d}$ Danxia Zhu ${ }^{a, c}$ Qi Zhou ${ }^{a}$ Jingting Jiang ${ }^{a, b, c, d}$ \\ Changping $\mathrm{Wu}^{\mathrm{a}, \mathrm{b}, \mathrm{c}}$
}

aDepartment of Oncology, the Third Affiliated Hospital of Soochow University, Changzhou, ${ }^{b}$ Institute of Cell Therapy, Soochow University, Changzhou, cJiangsu Engineering Research Center for Tumor Immunotherapy, Changzhou, 'Department of Biological Treatment, the Third Affiliated Hospital of

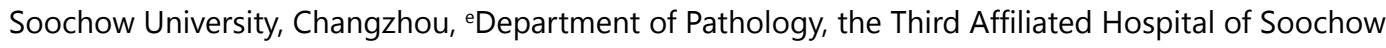
University, Changzhou, China

\section{Key Words}

LUAD $\cdot \mathrm{IL}-1 \beta \cdot \operatorname{miR}-144-3 p \cdot$ Proliferation

\begin{abstract}
Background/Aims: IL-1 $\beta$ is an important mediator of "inflammation-cancer" transformation through IL-1 $\beta / \mathrm{NF}-\mathrm{kB} / \mathrm{COX}-2 / \mathrm{HIF}-1 \alpha$ signaling pathway, whereas certain portion of patients with lung adenocarcinoma (LUAD) still suffer from rapid tumor progression in clinical practice, indicating the occurrence of potential bypass. Methods: Real-time polymerase chain reaction was applied to examine the expressions of mir-144-3p, WT1, NF-kB, COX2 and HIF-1 $\alpha$ at the mRNA level in 127 LUAD samples and corresponding adjacent tissues. miR-144-3p mimic and antagormiR were used to trigger activation and suppression of miR-144-3p in A549 cells, respectively. MTT assay and Western blotting analysis were carried out to evaluate the cell proliferation. Stable clones with over-expression or knockdown of WT1 were generated with plasmid or shRNA by lentiviral vector technology in H1568 and H1650 NSCLC cell lines, respectively. Dual luciferase reporter assay was performed to validate the effect of miR-144$3 p$ on WT1D. Xenograft model was established for in vivo experiment, and TCGA data were extracted for validation. Results: miR-144-3p could suppress the WT1D expression at the post-transcriptional level, hence regulating cell proliferation in LUAD. WT1 and COX-2 were independent prognostic factors of LUAD patients. In addition, inhibition of IL-1 $\beta / \mathrm{miR}-144-$ $3 p / W T 1 D$ and IL-1 $\beta / N F-k B / C O X-2 / H I F-1 \alpha$ pathways using miR-144-3p mimic and Celecoxib,

C. Wu and X. Li contributed equally to this work.

\begin{tabular}{ll}
\hline Jingting Jiang & The Third Affiliated Hospital of Soochow University; Institute of Cell Therapy, Soochow University \\
and Changping Wu & No.185, Juqian Street, Changzhou, Jiangsu Province 213003 (China) \\
& Tel. 86-519-68870884, Fax 86-519-68870884, E-Mail Jiangjingting@suda.edu.cn; wcpjjt@163.com
\end{tabular}
\end{abstract}


respectively, displayed synergistic suppressive effect on cell proliferation in LUAD. Conclusion: A de novo IL-1 $\beta /$ miR-144-3p/WT1D axis was involved in proliferative regulation of LUAD.

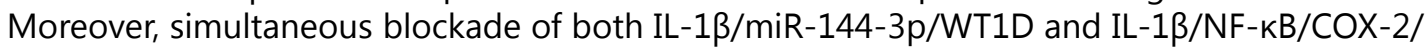
HIF-1 $\alpha$ pathways might have synergistic suppressive effect on cell proliferation in LUAD.

(C) 2018 The Author(s)

Published by S. Karger AG, Basel

\section{Introduction}

Lung cancer remains the leading cause of cancer-related death worldwide, and its case number is constantly increasing [1]. Great efforts have been made to increase clinical benefits, and promising results have been achieved in patients harboring driver mutations and immunological specificity using targeted and immunotherapies, respectively. Non-small-cell lung cancer (NSCLC) accounts for about $85 \%$ of lung cancer, of which lung adenocarcinoma (LUAD) accounts for 60\% [2].

Chronic inflammation and infection have been established as pivotal factors of carcinogenesis [3-7]. Although evidence has demonstrated significant relationship between tumor development and focal (systemic) inflammation in LUAD [8], the underlying mechanism remains largely unexplored. Interleukin-1 beta (IL-1 $\beta$ ) is a member of the IL-1 cytokine family that is produced by activated macrophages as a pro-protein and processed to its active form by caspase 1 [9]. The induction of cyclooxygenase-2 (PTGS2/COX2) by IL$1 \beta$ in the central nervous system (CNS) contributes to inflammatory pain hypersensitivity [10]. Our previous study has demonstrated that in LUAD patients, the serum IL-1 $\beta$ level is correlated with miR-144-3p, and such correlation may affect the miR-144-3p expression at the transcriptional level. Both of IL-1 $\beta$ and miR-144-3p are independent risk factors for prognosis of LUAD. In addition, IL-1 $\beta$ and miR-144-3p may mediate inflammation-promoted proliferation in LUAD patients [11]. Based on above-mentioned findings, we wondered via which target gene IL-1 $\beta$ and miR-144-3p regulated the proliferation and how IL- $1 \beta / \mathrm{miR}$ 144-3p pathway was linked to IL-1 $\beta / \mathrm{NF}-\kappa \mathrm{B} / \mathrm{COX}-2 / \mathrm{HIF}-1 \alpha$ pathway.

In this study, we found that WT1D was a potential target of miR-144-3p, and both in vitro and in vivo experiments confirmed that IL-1 $\beta$ and miR-144-3p regulated the cell proliferation in LUAD through WT1D. WT1 and COX-2 were prognostic factors of LUAD patients according to the Cancer Genome Atlas (TCGA) database. In addition, simultaneous blockade of both IL$1 \beta /$ miR-144-3p/WT1D and IL-1 $\beta / \mathrm{NF}-\kappa \mathrm{B} / \mathrm{COX}-2 / \mathrm{HIF}-1 \alpha$ pathways might have synergistic suppressive effect on cell proliferation in LUAD.

\section{Materials and Methods}

Patients, samples, cell lines and animals

A total of 127 randomly selected LUAD patients were enrolled in the present study. Specimens were collected from the Third Affiliated Hospital of Soochow University (Changzhou, China) during biopsy and surgery, and freshly collected samples were immediately frozen in liquid nitrogen or fixed in formaldehyde. Informed consent was obtained from each participant, and our study was approved by the Ethics Committee of Human Experimentation. All specimens were histologically and blindly classified by two professional pathologists according to the national NCCN guidelines for NSCLC.

The human NSCLC cell line A549 was obtained from American Type Culture Collection (ATCC, USA) and cultured according to the guideline.

A total of 20 4-week-old Balb/cnu/nu mice were purchased from Model Animal Research Center of Nanjing University, China. Animals were bred in an SPF-grade animal breeding facility of Soochow University.

\section{TCGA database}

The expression profiles of WT1, NF- $\kappa \mathrm{B}, \mathrm{COX}-2$ and HIF- $1 \alpha$ as well as clinical information of LUAD samples were obtained from TCGA database, including 452 LUAD patients. The K-means clustering analysis $(\mathrm{K}=2)$ was carried out to categorize the patients into two groups based on expressions of WT1, NF- $\kappa B$, 


\section{Cellular Physiology Cell Physiol Biochem 2018;48:2493-2502 \begin{tabular}{l|l|l} 
and Biochemistry Published online: 16 August, 2018 & $\begin{array}{l}\text { @ } 2018 \text { The Author(s). Published by S. Karger AG, Basel } \\
\text { www.karger.com/cpb }\end{array}$ \\
\hline
\end{tabular}}

Wu et al.: IL-1 $\beta$, Mir-144-3p and WT1D Regulate Cell Proliferation in LUAD

COX-2 and HIF-1 $\alpha$. The log-rank test and Kaplan-Meier curve were employed to evaluate the statistical significance and prognosis of the two groups.

Cell culture, miR-144-3p mimic and antagomiR transfection

LUAD cell line A549 and human embryo kidney cell line 293T were employed for in vitro experiments and cultured according to manufacturer's instructions. A549 cells were treated with $10 \mathrm{ng} / \mathrm{mL}$ IL-1 $\beta$ (PrimeGene, catalog No. 101-01B). Mimic (catalog No. miR10000436-1-5) and antagomiR (catalog No. miR30000436-1-10) were purchased from Ribobio Co., Ltd.

miRNA isolation and cDNA synthesis

Total RNA was isolated from cells using Trizol reagent (Invitrogen, catalog No. 15596018) according to the manufacturer's instructions. RNA concentration and integrity were examined by Beckman Coulter DU800 spectrophotometer (Beckman). Purified RNA was reversely transcribed into cDNA with a Primescript ${ }^{\mathrm{TM}}$ RT reagent kit (TaKaRa, catalog No. RR014A). Briefly, a 40- $\mu \mathrm{L}$ reaction system consisting of $12 \mu \mathrm{L}$ total RNA, $8 \mu \mathrm{L}$ Primescript buffer and $20 \mu \mathrm{L}$ DEPC-treated water was incubated at $37^{\circ} \mathrm{C}$ for $15 \mathrm{~min}$, followed by incubation at $85^{\circ} \mathrm{C}$ for $5 \mathrm{~s}$, and the newly synthesized cDNA was stored at $4^{\circ} \mathrm{C}$ prior to further analysis.

\section{Real-time PCR}

The expression of miR-144-3p was quantified by qRT-PCR using Bulge-Loop ${ }^{\text {TM }}$ miRNA qRT-PCR Primer Set (Ribobio, catalog No. miRQ0000436-1-2). The expressions of WT1, NF- $\kappa B$, COX2, HIF- $1 \alpha$ and $\beta$-actin were examined by qRT-PCR using the following primers (WT1: F 5'-GCTATTCGCAATCAGGGTTACAG-3', R 5'-TGGGATCCTCATGCTTGAATG-3'; NF-кB: F 5'-CTGAACCAGGGCATACCTGT-3', R 5'-GAGAAGTCCATGTCCGCAAT-3';COX2:F5'-GCACCCCGACATAGAGAGC-3',R5'-CTGCGGAGTGCAGTGTTCT-3'; HIF-1 $\alpha: \quad$ F 5 '-TTCCCGACTAGGCCCATTC-3', $\quad \mathrm{R} \quad$ 5'-CAGGTATTCAAGGTCCCATTTCA-3'; $\beta$-actin : $\quad$ F 5'-CCCAGCACAATGAAGATCAAGATCAT-3', R 5'-ATCTGCTGGAAGGTGGACAGCGA-3'). The relative expression levels of target genes were analyzed and expressed by ${ }^{\triangle \Lambda} \mathrm{CT}$ method.

\section{Western blotting analysis}

Total proteins were extracted using CHAPS lysis buffer. Equal amounts of proteins were subjected to sodium dodecyl sulfate polyacrylamide gel electrophoresis (SDS-PAGE) and then transferred onto polyvinylidene fluoride (PVDF) membrane. Blots were blocked in 4\% dry milk at room temperature for $1 \mathrm{~h}$, followed by incubation with different primary antibodies [anti-WT1 (6F-H2), 1:1, 500, Dako, catalog No. M356101-2; anti-NF- $\mathrm{B}$ (P65), 1:2, 000, Cell signaling Technology, catalog No. 4764S; anti-COX2, 1:2, 000, Cell signaling Technology, catalog No. 4842; anti-HIF-1 $\alpha, 1: 1,500$, Cell signaling Technology, catalog No. 3716; anti-PCNA, 1:2, 000, Cell signaling Technology, catalog No. 13110; $\beta$-actin 1:10, 000; Cell signaling Technology, catalog No. 4967) at $4^{\circ} \mathrm{C}$ overnight. The immunoreactive bands were visualized via a chemiluminescent detection system (Pierce ECL Substrate Western-blot detection system; Thermo, catalog No. 35050) and exposed in Molecular Imager ChemiDoc XRS System (Bio-Rad, Hercules).

\section{MTT assay}

Cell proliferation was determined using Vybrant MTT Cell Proliferation Assay Kit (Invitrogen, catalog No. V13154). Cells were collected at 0, 24, 48 and $72 \mathrm{~h}$ after Celecoxib exposure and miR-144-3p mimic transfection. Absorbance at a wavelength of $570 \mathrm{~nm}$ was determined by a spectrometer. The experiment was performed in triplicates.

\section{Tumorigenicity in nude mice}

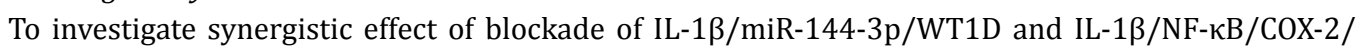
HIF-1 $\alpha$ pathways on tumor growth, xenograft model was established in 4 -week-old Balb/ $\mathrm{C}^{\mathrm{nu} / \mathrm{nu}}$ mice for in vivo experiment. Briefly, A549 cells were trypsinized, resuspended in $100 \mu \mathrm{L}$ PBS containing $50 \mu \mathrm{L}$ Matrigel (BD, catalog No. 356234) and subcutaneously injected into the axilla of each nude mouse $\left(5 \times 10^{6}\right.$ cells per mouse). When tumor size reached $5 \mathrm{~mm} \times 5 \mathrm{~mm}$ at 1 week post-injection, 20 mice with similar tumor volume were randomly selected and divided into four groups (Ctrl, Celecoxib, miR-144-3p agomiR, and Celecoxib plus miR-144-3p agomiR). Celecoxib (Pfizer) was dissolved in 75\% ethanol and diluted in clear water to a final concentration of $0.25 \mathrm{mg} / \mathrm{mL}$. miR-144-3p agomiR was dissolved in RNAse free PBS and diluted to 4.35 


\section{Cellular Physiology Cell Physiol Biochem 2018;48:2493-2502 \begin{tabular}{l|l|l} 
and Biochemistry & DOI: 10.1159/000492687 & $\begin{array}{l}\text { C) } 2018 \text { The Author(s). Published by S. Karger AG, Basel } \\
\text { www.karger.com/cpb }\end{array}$
\end{tabular}}

Wu et al.: IL-1 $\beta$, Mir-144-3p and WT1D Regulate Cell Proliferation in LUAD

$\mu \mathrm{M}$ for intravenous tail injection (50 $\mu \mathrm{L}$, day 0 \& day 12). Tumor dimensions were measured every 4 days, all mice were sacrificed after 24 days, and tumors were dissected. The tumor volume was calculated using following formula: volume $=$ length $\times$ width $^{2} \times 0.5$.

\section{Immunohistochemistry (IHC)}

Tissues were fixed in 4\% paraformaldehyde and cut from paraffin-embedded block to $5 \mu \mathrm{m}$ sections. After dewaxing with xylene and rehydration in a graded series of ethanol, the slides were heated in the autoclave for 3 min using citrate buffer ( $\mathrm{pH} \mathrm{6.0)}$ and incubated with primary antibodies against NF- $\mathrm{KB}$ (1:200, Cell Signaling Technology, catalog No. 8242), COX-2 (1:400, Cell Signaling Technology, catalog No. 12282), HIF-1 $\alpha$ (1:200, Cell Signaling Technology, catalog No. 79233) and WT1 (1:200, 6F-H2, Millipore, catalog No. M356101-2) at $4^{\circ}$ overnight. Blocking serum or antibody dilution buffer was prepared as negative controls. Photographs were acquired by microscope (Nikon, ECLIPSE 50i) and software NIS-Elements v4.0. Immunostaining was scored by two pathologists using H-score method.

\section{Lentiviral production and transduction}

WT1D gene was synthesized (purchased from Genscript, China) with restrictive digestion using Mlu I, subcloned into pLV-GFP plasmid and named pLV-GFP-WT1. To generate plasmid expressing WT1-shRNA, double-stranded oligonucleotides were cloned into pLL3.7 vector and named pLL3.7-shWT1. The sequence of WT1-shRNA was acTCAGGGTTACAGCACGGTCttcaagagaGACCGTGCTGTAACCCTGAttttttc. The uppercase letters represent WT1 specific sequence, and lowercase letters represent hairpin sequences. Recombinant lentivirus was generated from $293 \mathrm{~T}$ cells using calcium phosphate precipitation. A549 cells were transfected with lentivirus using polybrene $(8 \mu \mathrm{g} / \mathrm{mL})$.

\section{Luciferase reporter assay}

A dual-luciferase reporter assay was performed to investigate the transcriptional regulation of WT1D by miR-144-3p. The 3' UTR of WT1D containing miR-144-3p binding site (UACUGUA) was synthesized artificially and named WT1D 3' UTR. The 3' UTR with the mutated binding site (GCACGCA) was also synthesized and named WT1D 3'UTR-mut (Fig. 1E). Products were validated via agarose gel electrophoresis and cloned into the luciferase reporter vector (Promega, Madison, WI). A549 cells were seeded into 24-well plates and co-transfected with miR-144-3p mimic (marked as “个”), miR-144-3p antagoR (marked as “ $\downarrow$ ”) or control miRNA (marked as “-') respectively and luciferase reporter vector using Lipofectamine ${ }^{\mathrm{TM}} 2000$ (Invitrogen, catalog No. 11668019) following the manufacturer's instructions. At 0, 6, 12, 24 and $48 \mathrm{~h}$ after incubation, firefly and Renilla luciferase activities were determined with the dual luciferase reporter assay system (Promega, catalog No. E1910). All results were obtained from three independent experiments.

\section{Statistical analysis}

Statistical analysis was performed using GraphPad Prism (version 5.01; GraphPad Software) and SPSS (version 17, SPSS Inc) statistical software. The Student's t-test and paired t-test were used to analyze significance between independent groups and paired materials, respectively. The $\chi 2$ test was used to assess the significance of observed differences in proportions except when the cell size was less than 5 (Fisher's exact tests). Survival curves were made using the Kaplan-Meier method and compared using the log-rank test. All variables that achieved significance at $P \leq 0.05$ in univariate analyses were enrolled in multivariate Cox's proportional hazard model. $P \leq 0.05$ was considered as statistically significant unless otherwise specified.

\section{Results}

Our previous work has demonstrated that in LUAD patients, the IL- $1 \beta$ level is correlated with miR-144-3p, and such correlation can affect the miR-144-3p expression at the transcriptional level. Both of them are associated with prognosis and independent risk factors for LUAD patients. In addition, IL-1 $\beta$ may promote cell proliferation via suppression of miR-144-3p. Via web tool http://alggen.lsi.upc.es/cgi-bin/promo_v3/promo/ promo.cgi? $\operatorname{dirDB}=\mathrm{TF}$ _8.3\&calledBy=alggen, one potential miR-144-3p binding site has been predicted 
in WT1D 3' UTR. Moreover, IL-1 $\beta$-mediated up-regulation of HIF-1 $\alpha$ via an NF- $\kappa \mathrm{B} / \mathrm{COX}-2$ pathway has been identified, and an IL-1 $\beta /$ NF- $\mathrm{KB} / \mathrm{COX}-2 / \mathrm{HIF}-1 \alpha$ pathway may be a critical link between inflammation and oncogenesis. As a result, we hypothesized that a potential IL$1 \beta /$ miR-144-3p/WT1D pathway might be involved in proliferative regulation and crosstalk with IL-1 $\beta /$ NF- $\kappa$ B/COX-2/HIF-1 $\alpha$ pathway of LUAD.

WT1 expression is suppressed by miR-144-3p at the post-transcriptional level

miR-144-3p mimic or antagomiR could suppress or enhance the WT1 expression at the protein level, respectively (Fig. 1A\&B). IL-1 $\beta$ suppressed miR-144-3p and enhanced WT1 expression (Fig. 1A, B\&D). Over-expression or silencing of WT1 by plv-GFP-WT1D or pLL3.7shWT1 displayed limited effect on miR-144-3p, respectively (Fig. 1C). The luciferase activity in A549 cells over-expressing miR-144-3p was decreased (Fig. 1F), while it was increased after suppression of miR-144-3p (Fig. 1G). The enhancive (attenuative) effect of miR-144-3p on WT1 3' UTR was crippled when WT1 3' UTR was mutated (Fig. 1H).

miR-144-3p suppresses tumor proliferation and had synergistic effect on COX-2 inhibition

In vitro study showed that Celecoxib and miR-144-3p mimic both suppressed cell proliferation $(P<0.001)$, and their combination even more significantly suppressed cell proliferation compared with the mono-treatment $(P<0.0001)$ (Fig. 2A). WT1 expression was increased when IL-1 $\beta /$ NF- $\kappa B / C O X-2 /$ HIF-1 $\alpha$ pathway was suppressed by Celecoxib. Similarly, COX-2 expression was increased after exposure to miR-144-3p mimic, indicating that IL-1 $\beta$ / NF- $\mathrm{kB} / \mathrm{COX}-2 / \mathrm{HIF}-1 \alpha$ and IL-1 $\beta / \mathrm{miR}-144$ $3 \mathrm{p} /$ WT1D pathways existed downstream of IL-1 $\beta$ (Fig. 2B). PCNA protein was also suppressed by Celecoxib and miR-144-3p over-expression, which was consistent with MTT result (Fig. 2B). In vivo experiment exhibited that the combination therapy suppressed subcutaneous implant most significantly (Fig. 2C\&D).

Prognosis evaluation between different groups of LUAD patients

Fig. 3 shows that positive staining of NF- $\mathrm{BB}, \mathrm{COX}-2, \mathrm{HIF}-1 \alpha$ and WT1 was detected in all patients.

Based on TCGA database, patients with low WT1 (Fig. 4A) and high COX-2 (Fig. 4C) levels showed better prognosis compared with their counterparts, respectively, which validated our findings. Besides, patients with high HIF-1 $\alpha$ (Fig. 4D) level also showed longer survival.

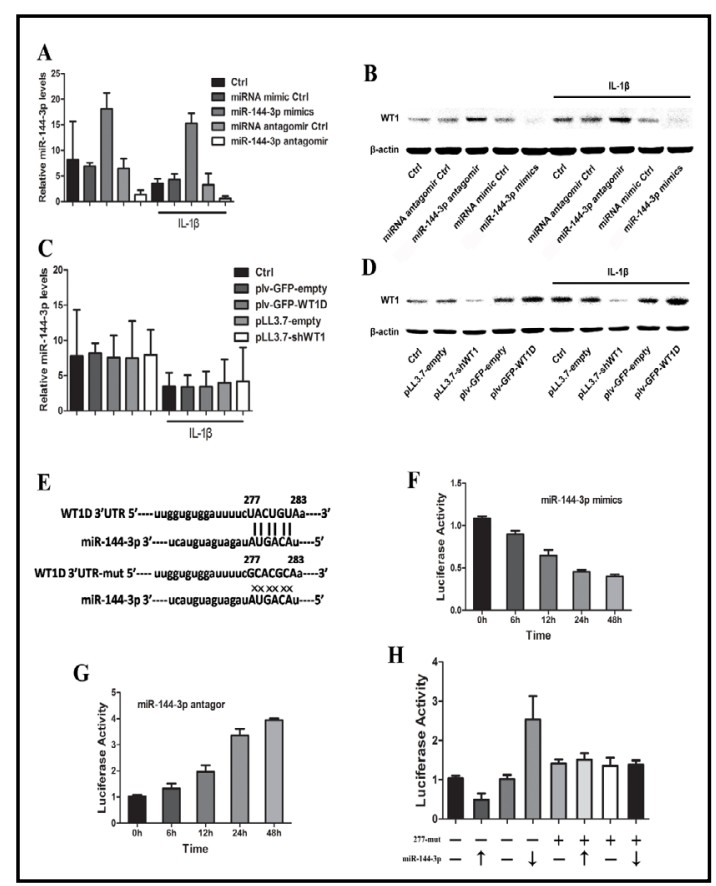

Fig. 1. miR-144-3p suppresses WT1 expression at the post-transcriptional level. The expression of WT1 at the protein level was significantly downregulated when miR-144-3p expression was enhanced by mimic, while it was up-regulated when miR-144-3p was suppressed by antagomir (B). IL-1 $\beta$ exposure could suppress miR-144-3p, but enhance WT1 expression (A, B\&D). miR-144-3p expression at the mRNA level varied slightly after WT1 over-expression or silencing by plv-GFP-WT1D or pLL3.7-shWT1, respectively (C). The structures of wild-type or mutated WT1D 3' UTR (WT1D 3' UTR \& WT1D 3' UTR-mut) were synthesized artificially and illustrated (E). The luciferase activity in A549 cells was deceased after miR-144-3p over-expression (F) and increased after suppression $(G)$. The enhancive (attenuative) effect of miR-144-3p on WT1 3' UTR was crippled when WT1 3' UTR was mutated $(\mathrm{H})$. 
Fig. 2. miR-144-3p suppresses tumor proliferation and has synergistic effect with Celecoxib. In vitro and vivo experiments showed that Celecoxib and miR144-3p mimic suppressed cell proliferation $(\mathrm{P}<0.001)(\mathrm{A}, \mathrm{C} \& \mathrm{D})$, and the combination of Celecoxib and miR-144-3p silencing suppressed the proliferation more significantly compared with monotreatment $(\mathrm{P}<0.0001) \quad(\mathrm{A}, \mathrm{C} \& \mathrm{D})$. Western blotting analysis showed key protein expressions in IL-1 $\beta$ / NF- $\kappa B / C O X-2 / H I F-1 \alpha$ and IL-1 $\beta$ /

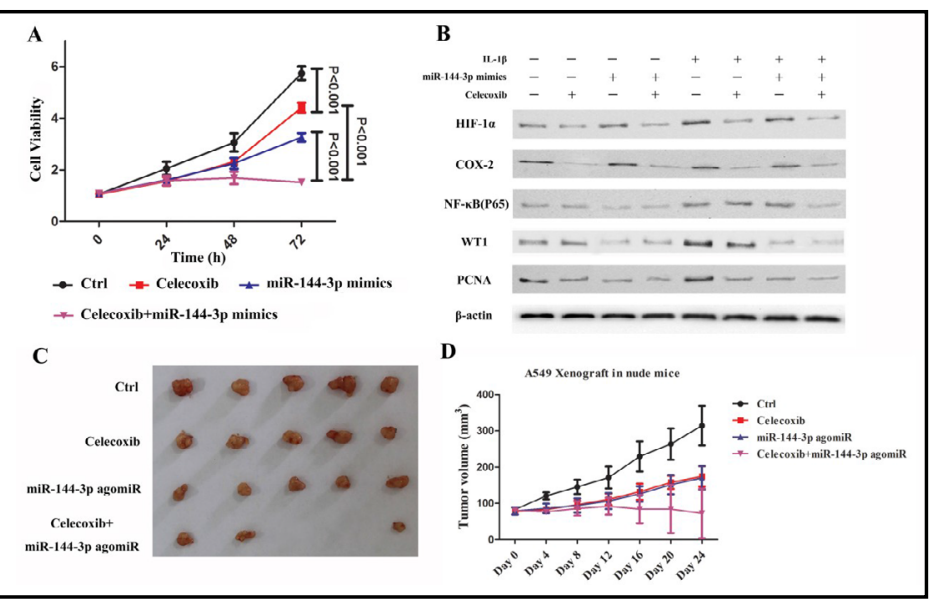
miR-144-3p/WT1D pathways after exposure of IL-1 $\beta$ and Celecoxib and miR-144-3p over-expression (B).

Fig. 3. Protein expressions in typical cases. Proteins in IL-1 $\beta /$ miR-144-3p/WT1D and IL-1 $\beta /$ NF- $\kappa$ B/COX-2/HIF-1 $\alpha$ pathways were detected via IHC. NF- $\mathrm{BB}$, COX-2, HIF- $1 \alpha$ and WT1D were all negative in patient $\mathrm{C} 6$, while they were all positive in patients $A 8$ and C8. In patient $\mathrm{C} 2, \mathrm{NF}-\kappa \mathrm{B}$ and WT1D were positive, while COX-2 and HIF-1 $\alpha$ were negative.

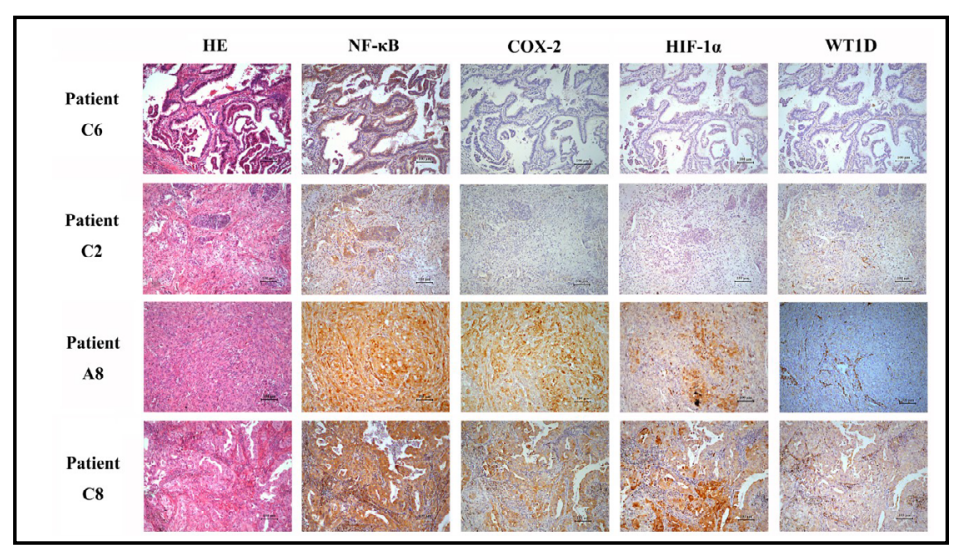

Patients with low WT1 level (Fig. 5A), high COX-2 level (Fig. 5C), early stage (stage 1-2) (Fig. 5E) and past history of TKI therapy (Fig. 5F) showed better prognosis compared with those with their counterparts $(P<0.001)$, whereas no significant differences in prognosis were observed between patients with high and

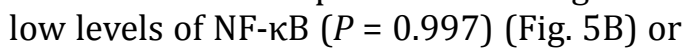
HIF-1 $\alpha(P=0.534)$ (Fig. 5D).

By $\chi 2$ test, we confirmed that WT1 was correlated with clinical stage and TKI treatment in LUAD patients (Table 1). Univariate analysis showed that clinical stage, TKI therapy, WT1 level and COX-2 level were significant prognostic factors, while age, gender, smoking status, NF$\kappa \mathrm{B}$ and HIF-1 $\alpha$ displayed no statistical differences (Table 2). As an association was determined between WT1 level and clinical stage, and two separate multivariate models (WT1 and clinical stage) were run to avoid

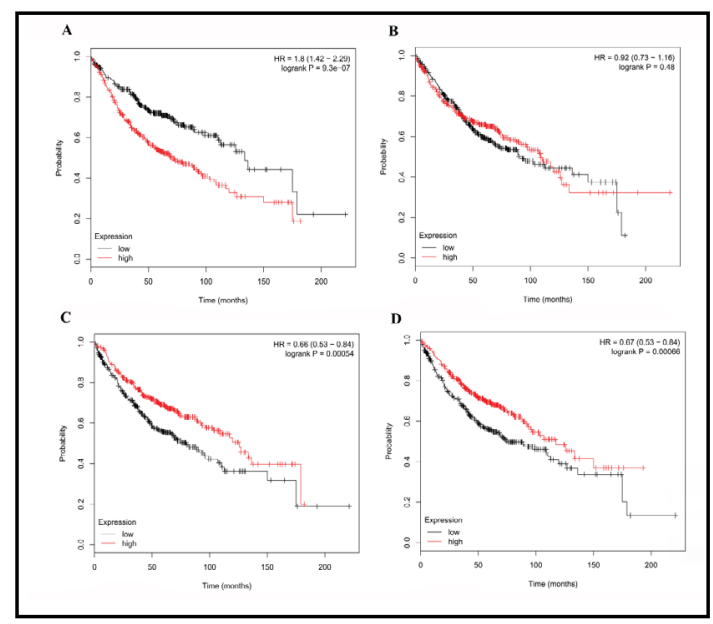

Fig. 4. Prognostic analysis of TCGA data. Patients with low WT1 (A), high COX-2 (C) and high HIF$1 \alpha$ (D) levels showed better prognosis than their counterpart, respectively; no significant prognositic difference between high and low NF- $\kappa \mathrm{B}$ groups. 


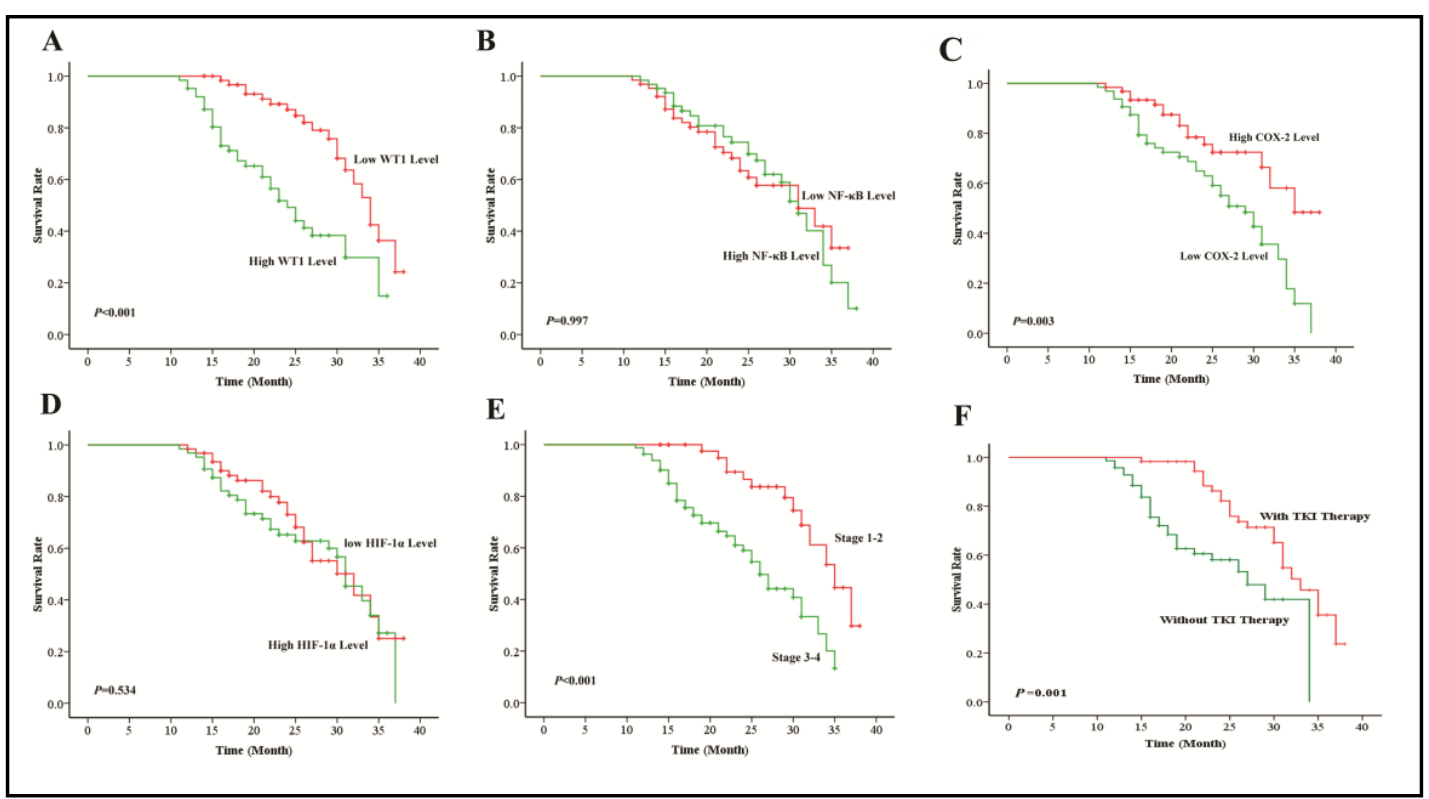

Fig. 5. Prognosis evaluation between different groups of LUAD patients. Patients with low WT1 level (A), high COX-2 level (C), early stage (stage 1-2) (E) and past history of TKI therapy (F) showed better prognosis compared with those with their counterparts $(\mathrm{P}<0.001)$, whereas no significant differences in prognosis were observed between patients with high and low NF- $\mathrm{BB}(\mathrm{P}=0.997)(\mathrm{B})$ or HIF-1 $\alpha$ levels $(\mathrm{P}=0.534)(\mathrm{D})$.

Table 1. Clinical features of LUAD patients

\begin{tabular}{|c|c|c|c|c|c|c|c|c|c|c|c|c|c|}
\hline \multirow[b]{2}{*}{ Characteristics } & \multirow[b]{2}{*}{ All patients } & \multicolumn{3}{|c|}{ WT1 } & \multicolumn{3}{|c|}{ NF-kB } & \multicolumn{3}{|c|}{$\operatorname{cox} 2$} & \multicolumn{3}{|c|}{ HIF-1 } \\
\hline & & $\begin{array}{c}\text { Low } \\
(0-1)\end{array}$ & $\begin{array}{l}\text { High } \\
(2-3)\end{array}$ & $\mathrm{P}$ & $\begin{array}{c}\text { Low } \\
(0-1)\end{array}$ & $\begin{array}{l}\text { High } \\
(2-3)\end{array}$ & $\mathrm{P}$ & $\begin{array}{c}\text { Low } \\
(0-1)\end{array}$ & $\begin{array}{l}\text { High } \\
(2-3)\end{array}$ & $\mathrm{P}$ & $\begin{array}{l}\text { Low } \\
(0-1)\end{array}$ & $\begin{array}{l}\text { High } \\
(2-3)\end{array}$ & $\mathrm{P}$ \\
\hline $\mathrm{n}$ & 127 & 64 & 63 & 0.997 & 64 & 63 & 0.997 & 64 & 63 & 0.997 & 64 & 63 & 0.997 \\
\hline Age (year) & 64 & 64 & 63 & 0.947 & 62 & 65 & 0.947 & 65 & 62 & 0.842 & 62 & 65 & 0.842 \\
\hline Median (range) & $(49-82)$ & $(49-82)$ & $(49-82)$ & & $(49-82)$ & $(49-82)$ & & $(49-82)$ & $(49-82)$ & & $(50-81)$ & $(49-82)$ & \\
\hline Gender & & & & 0.454 & & & 0.649 & & & 0.392 & & & 0.454 \\
\hline Female & $34(26.8 \%)$ & $19(15.0 \%)$ & $15(11.8 \%)$ & & $16(12.6 \%)$ & $18(14.2 \%)$ & & $19(15.0 \%)$ & $15(11.8 \%)$ & & $15(11.8 \%)$ & $19(15.0 \%)$ & \\
\hline Male & $93(73.2 \%)$ & $45(35.4 \%)$ & $48(37.8 \%)$ & & $48(37.8 \%)$ & $45(35.4 \%)$ & & $44(34.6 \%)$ & $49(38.6 \%)$ & & $48(37.8 \%)$ & $45(35.4 \%)$ & \\
\hline Smoke & & & & 0.232 & & & 0.950 & & & 0.232 & & & 0.753 \\
\hline No & $42(33.1 \%)$ & $18(14.2 \%)$ & $24(18.9 \%)$ & & $21(16.5 \%)$ & $21(16.5 \%)$ & & $24(18.9 \%)$ & $18(14.2 \%)$ & & $20(15.7 \%)$ & $22(17.3 \%)$ & \\
\hline Yes & $85(66.9 \%)$ & $46(36.2 \%)$ & $39(30.7 \%)$ & & $43(33.9 \%)$ & $42(33.1 \%)$ & & $39(30.7 \%)$ & $46(36.2 \%)$ & & $43(33.9 \%)$ & $42(33.1 \%)$ & \\
\hline Clinical Stage & & & & $<0.001$ & & & 0.123 & & & 0.647 & & & 0.401 \\
\hline I & $10(7.9 \%)$ & $5(3.9 \%)$ & $5(3.9 \%)$ & & $4(3.1 \%)$ & $6(4.7 \%)$ & & $7(5.5 \%)$ & $3(2.4 \%)$ & & $5(3.9 \%)$ & $5(3.9 \%)$ & \\
\hline II & $35(27.6 \%)$ & $26(20.5 \%)$ & $9(7.1 \%)$ & & $14(11.0 \%)$ & $21(16.5 \%)$ & & $17(13.4 \%)$ & $18(14.2 \%)$ & & $14(11.0 \%)$ & $21(16.5 \%)$ & \\
\hline III & $31(24.4 \%)$ & $20(15.7 \%)$ & $11(8.7 \%)$ & & $21(16.5 \%)$ & & & $15(11.8 \%)$ & $16(12$ & & $19(15.0 \%)$ & $12(9.4 \%)$ & \\
\hline IV & $51(40.2 \%)$ & $13(10.2 \%)$ & $38(29.9 \%)$ & & $25(19.7 \%)$ & $26(20.5 \%)$ & & $24(18.9 \%)$ & $27(21.3 \%)$ & & $25(19.7 \%)$ & $26(20.5 \%)$ & \\
\hline Early/Late stage & & & & $<0.001$ & & & 0.172 & & & 0.321 & & & 0.389 \\
\hline Early (IA-1 & $45(35.4 \%)$ & $32(25.2 \%)$ & $13(10.2 \%)$ & & $19(15.0 \%)$ & $26(20.5 \%)$ & & $25(19.7 \%)$ & $20(15.7 \%)$ & & $20(15.7 \%)$ & $25(19.7 \%)$ & \\
\hline Late (IIIA-IVB) & $82(64.6 \%)$ & $32(25.2 \%)$ & $50(39.4 \%)$ & & $45(35.4 \%)$ & $37(29.1 \%)$ & & $38(29.9 \%)$ & $44(34.6 \%)$ & & $43(33.9 \%)$ & $39(30.7 \%)$ & \\
\hline EGFR mutation & & & & 0.058 & & & 0.797 & & & 0.646 & & & 0.646 \\
\hline Yes & $72(56.7 \%)$ & $31(24.4 \%)$ & $41(32.3 \%)$ & & $37(29.1 \%)$ & $35(27$ & & $37(29.1 \%)$ & $35(27.6 \%)$ & & $37(29.1 \%)$ & $35(27.6 \%)$ & \\
\hline No & $55(43.3)$ & $33(26.0 \%)$ & $22(17.3 \%)$ & & $27(21.3 \%)$ & $28(22.0 \%)$ & & $26(20.5 \%)$ & $29(22.8 \%)$ & & $26(20.5 \%)$ & $29(22.8 \%)$ & \\
\hline TKI tr & & & & 0.025 & & & 0.417 & & & 0.538 & & & 0.922 \\
\hline Yes & $70(55.1 \%)$ & $29(22.8 \%)$ & $41(32.3 \%)$ & & $33(26.0 \%)$ & $37(29.1 \%)$ & & $33(26.0 \%)$ & $37(29.1 \%)$ & & $35(27.6 \%)$ & $35(27.6 \%)$ & \\
\hline No & $57(44.9 \%)$ & $35(27.6 \%)$ & $22(17.3 \%)$ & & $31(24.4 \%)$ & $26(20.5 \%)$ & & $30(23.6 \%)$ & $27(21.3 \%)$ & & $28(22.0 \%)$ & $29(22.8 \%)$ & \\
\hline
\end{tabular}

problems of multicollinearity. Multivariate analyses demonstrated that clinical stage, TKI therapy, WT1 and COX-2 were independent risk factors for overall survival (Table 2).

\section{Discussion}

Serum IL-1 $\beta$ level has been correlated with miR-144-3p, and such correlation affects the miR-144-3p expression at the transcriptional level. Both of them are independent risk factors for prognosis of LUAD [11]. In the present study, we demonstrated that a de novo IL$1 \beta /$ miR-144-3p/WT1D axis was involved in proliferative regulation of LUAD. Such finding was also validated by clinical data from both LUAD patients and TCGA database. In addition, simultaneous blockade of both IL-1 $\beta /$ miR-144-3p/WT1D and IL-1 $\beta / N F-\kappa B / C O X-2 / H I F-1 \alpha$ pathways might have synergistic effect on suppression of cell proliferation in LUAD. 
IL-1 $\beta$ has been identified as pivotal cytokine in inflammation initiation and an important mediator of the inflammatory response [9]. The induction of COX- 2 by IL- $1 \beta$ in the CNS contributes to inflammatory pain hypersensitivity [10]. In tumor initiation and development, it has been proved that IL-1 $\beta$ can activate HIF- $1 \alpha$ via $\mathrm{NF}-\kappa \mathrm{B}$ and COX-2, making it a signaling bridge between inflammation and malignancy [12]. COX-2 expression induced by IL$1 \beta$ can be inhibited by nonsteroidal anti-inflammatory drugs (NSAIDs), such as synthetic COX-2 inhibitor "Celecoxib", leading to cancer cell apoptosis, which explains anti-cancer effect and mechanism of NSAIDs [13]. Besides, NSAIDs display certain therapeutic effect on solid tumors, including LUAD. Shin DM et al. have discovered that targeted therapy (Erlotinib) combined with Celecoxib can effectively block proliferation of tumor cells in G1 phase in head and neck malignancies [14]. Lyons TR et al. have demonstrated that COX-2 can promote lymphangiogenesis in postpartum breast carcinoma, thus increasing the risk of lymph node metastasis, and Celecoxib can effectively control lymphangiogenesis and improve its prognosis [15]. These findings suggest that IL-1 $\beta$ can mediate "inflammation to cancer" transformation through COX-2/HIF-1 $\alpha$, whereas NSAIDs can effectively suppress or postpone such process. Nevertheless, NVALT-4 trial has shown that Celecoxib does not prolong survival of NSCLC patients, and COX-2 is not an independent prognostic factor [16]. A certain portion of NSCLC patients can not benefit from NSAIDs, and they still suffer from rapid progression of tumor in clinical practice. Studies have confirmed that Celecoxib can promote epithelial-mesenchymal transition (EMT) of cancer cells, leading to increased metastatic risk [17]. Taken together, COX-2/HIF-1 $\alpha$ signaling was probably not the only IL-1 $\beta$ downstream pathway to promote cancer. Accordingly, NSAIDs might promote tumor progression in certain cases.

Our previous studies have demonstrated that IL-1 $\beta$ and miR-144-3p are involved in regulation of LUAD cell proliferation, suggesting an miRNA-related signaling bypass, which may explain the reason why certain portion of patients barely benefit from COX-2 inhibitor. WT1D is a direct target of miR-144-3p, and it has been demonstrated to be an oncogene in NSCLC, promoting cell proliferation and cancer progression. Therefore, we identified that WT1D was an important downstream molecule of IL-1 $\beta$ and miR-144-3p that promote cell proliferation in LUAD [11].

miRNA is involved in gene regulation and affects various cell biology processes, which is also commonly detected in occurrence and development of cancer [18-21]. As a result, changes of miRNA expression or activity might have significant effect on cell fate. miR-144$3 p$ is an newly identified miRNA that is involved in multiple steps of antimicrobial immunity and cancer development. miR-144-3p inhibits autophagy activation by targeting ATG4a, enhances BCG infection and provides potential targets for improved treatments [22]. In 


\section{Cellular Physiology Cell Physiol Biochem 2018;48:2493-2502 \begin{tabular}{l|l|l} 
and Biochemistry $10.1159 / 000492687$ & $\begin{array}{l}\text { C) 2018 The Author(s). Published by S. Karger AG, Basel } \\
\text { www.karger.com/cpb }\end{array}$ \\
\hline
\end{tabular}}

laryngeal squamous cell carcinoma, the expression of ETS-1 is negatively associated with miR-144-3p level and prognosis [23]. miR-144-3p may have an advanced regulatory role in gene expressions.

When one of two signaling pathways is blocked or suppressed, the other's function may be compensatorily enhanced to maintain the overall stability. Synergistic inhibitory effect usually occurs when multiple blockades are applied for two or more individual signaling pathways, such as combined immunotherapy of PD-1 and CTLA-4 monoclonal antibodies $[24,25]$. In the present scenario, the COX-2 expression at the protein level was markedly increased when IL-1 $\beta / \mathrm{miR}-144-3 p / W T 1 D$ pathway was suppressed by miR-144-3p mimic (Fig. 2B).

Collectively, our findings enriched the mechanisms underlying IL- $1 \beta$-mediated transformation of "inflammation-cancer", and provided the reason why NSAIDs owned dichotomous effect and strong evidence for miR-144-3p to be an LUAD marker.

\section{Acknowledgements}

The authors declared no potential conflicts of interest. This work was financially supported by the National Key Technology R\&D Program (No. 2015BAI12B12), National Natural Science Foundation of China (No. 31700792), Natural Science Foundation of Jiangsu Province (No. BE2016660; No. BK20130243), Changzhou Science and Technology Project (Applied Based Research, No. CJ20159021) and Research Support Plan for post-doctor of Jiangsu Province (1601057A, 1601088C).

\section{Disclosure Statement}

The authors declare to have no competing interests.

\section{References}

Siegel RL, Miller KD, Jemal A: Cancer statistics, 2016. CA Cancer J Clin 2016;66:7-30.

Herbst RS, Heymach JV, Lippman SM: Lung cancer. N Engl J Med 2008;359:1367-1380.

Coussens LM, Werb Z: Inflammation and cancer. Nature 2002;420:860-867.

Marx J: Cancer research. Inflammation and cancer: the link grows stronger. Science 2004;306:966-968.

Coffelt SB, de Visser KE: Cancer: Inflammation lights the way to metastasis. Nature 2014;507:48-49.

Grivennikov SI, Greten FR, Karin M: Immunity, inflammation, and cancer. Cell 2010;140:883-899.

Zhong Z, Sanchez-Lopez E, Karin M: Autophagy, Inflammation, and Immunity: A Troika Governing Cancer and Its Treatment. Cell 2016;166:288-298.

Qu P, Du H, Li Y, Yan C: Myeloid-specific expression of Api6/AIM/Sp alpha induces systemic inflammation and adenocarcinoma in the lung. J Immunol 2009;182:1648-1659.

Dinarello CA: A clinical perspective of IL-1beta as the gatekeeper of inflammation. Eur J Immunol 2011;41:1203-1217.

10 Vardeh D, Wang D, Costigan M, Lazarus M, Saper CB, Woolf CJ, Fitzgerald GA, Samad TA: COX2 in CNS neural cells mediates mechanical inflammatory pain hypersensitivity in mice. J Clin Invest 2009;119:287-294.

11 Wu C, Xu B, Zhou Y, Ji M, Zhang D, Jiang J: Correlation between serum IL-1beta and miR-144-3p as well as their prognostic values in LUAD and LUSC patients. Oncotarget 2016;7:85876-85887.

12 Jung YJ, Isaacs JS, Lee S, Trepel J, Neckers L: IL-1beta-mediated up-regulation of HIF-1alpha via an NFkappaB/COX-2 pathway identifies HIF-1 as a critical link between inflammation and oncogenesis. FASEB J 2003; 17:2115-2117.

13 Hou Z, Falcone DJ, Subbaramaiah K, Dannenberg AJ: Macrophages induce COX-2 expression in breast cancer cells: role of IL-1 beta autoamplification. Carcinogenesis 2011;32:695-702. 


\section{Cellular Physiology Cell Physiol Biochem 2018;48:2493-2502 \begin{tabular}{l|l|l} 
DOI: 10.1159/000492687 & $\begin{array}{l}\text { O 2018 The Author(s). Published by S. Karger AG, Basel } \\
\text { www.karger.com/cpb }\end{array}$
\end{tabular} \\ Wu et al.: IL-1 $\beta$, Mir-144-3p and WT1D Regulate Cell Proliferation in LUAD}

14 Shin DM, Zhang H, Saba NF, Chen AY, Nannapaneni S, Amin AR, Muller S, Lewis M, Sica G, Kono S, Brandes JC, Grist WJ, Moreno-Williams R, Beitler JJ, Thomas SM, Chen Z, Shin HJ, Grandis JR, Khuri FR, Chen ZG: Chemoprevention of head and neck cancer by simultaneous blocking of epidermal growth factor receptor and cyclooxygenase-2 signaling pathways: preclinical and clinical studies. Clin Cancer Res 2013;19:12441256.

15 Lyons TR, Borges VF, Betts CB, Guo Q, Kapoor P, Martinson HA, Jindal S, Schedin P: Cyclooxygenase-2dependent lymphangiogenesis promotes nodal metastasis of postpartum breast cancer. J Clin Invest 2014;124:3901-3912.

-16 Groen HJ, Sietsma H, Vincent A, Hochstenbag MM, van Putten JW, van den Berg A, Dalesio O, Biesma B, Smit HJ, Termeer A, Hiltermann TJ, van den Borne BE, Schramel FM: Randomized, placebo-controlled phase III study of docetaxel plus carboplatin with celecoxib and cyclooxygenase-2 expression as a biomarker for patients with advanced non-small-cell lung cancer: the NVALT-4 study. J Clin Oncol 2011;29:4320-4326.

17 Wang ZL, Fan ZQ, Jiang HD, Qu JM: Selective Cox-2 inhibitor celecoxib induces epithelial-mesenchymal transition in human lung cancer cells via activating MEK-ERK signaling. Carcinogenesis 2013;34:638-646.

18 Niu J, Xue A, Chi Y, Xue J, Wang W, Zhao Z, Fan M, Yang CH, Shao ZM, Pfeffer LM, Wu J, Wu ZH: Induction of miRNA-181a by genotoxic treatments promotes chemotherapeutic resistance and metastasis in breast cancer. Oncogene 2016;35:1302-1313.

19 Cramer DW, Elias KM: A prognostically relevant miRNA signature for epithelial ovarian cancer. Lancet Oncol 2016;17:1032-1033.

-20 Ma MZ, Chu BF, Zhang Y, Weng MZ, Qin YY, Gong W, Quan ZW: Long non-coding RNA CCAT1 promotes gallbladder cancer development via negative modulation of miRNA-218-5p. Cell Death Dis 2015;6:e1583.

21 Jin M, Zhang T, Liu C, Badeaux MA, Liu B, Liu R, Jeter C, Chen X, Vlassov AV, Tang DG: miRNA-128 suppresses prostate cancer by inhibiting BMI-1 to inhibit tumor-initiating cells. Cancer Res 2014;74:4183-4195.

-22 Guo L, Zhou L, Gao Q Zhang A, Wei J, Hong D, Chu Y, Duan X, Zhang Y, Xu G: MicroRNA-144-3p inhibits autophagy activation and enhances Bacillus Calmette-Guerin infection by targeting ATG4a in RAW264.7 macrophage cells. Plos One 2017;12:e0179772.

23 Zhang SY, Lu ZM, Lin YF, Chen LS, Luo XN, Song XH, Chen SH, Wu YL: miR-144-3p, a tumor suppressive microRNA targeting ETS-1 in laryngeal squamous cell carcinoma. Oncotarget 2016;7:11637-11650.

24 Homicsko K, Duraiswamy J, Doucey MA, Coukos G: Combine and Conquer: Double CTLA-4 and PD-1 Blockade Combined with Whole Tumor Antigen Vaccine Cooperate to Eradicate Tumors. Cancer Res 2016;76:6765-6767.

25 Probst HC, McCoy K, Okazaki T, Honjo T, van den Broek M: Resting dendritic cells induce peripheral CD8+ T cell tolerance through PD-1 and CTLA-4. Nat Immunol 2005;6:280-286. 